\title{
Redefining Tourism Governance in Raja Ampat: Sustainable Development Plus, Governance Index and Android Based App Open Access
}

\author{
Marlon Arthur Huwae ${ }^{1}$ \\ University of Papua - Indonesia \\ Fikri Muhamad Hanif and Klasina Rumbekwan ${ }^{2}$ \\ Department of Tourism, Raja Ampat Regency Government, West Papua - Indonesia
}

\begin{abstract}
To develop tourism sustainably in an emerging tourism destination especially Raja Ampat, there is a need to manage regional identity and develop governance arrangements that bond tourism development and community together. The government as a key initiator of community empowerment, needs to ensure its governance arrangements are efficient. This paper develops a framework to measure the effectiveness of regional governance for sustainable tourism development based on two main elements: sustainable development plus and tourism governance. Sustainable development plus consists of two core named internal and external layers. The tourism governance is then measured by data triangulation, and analysis. The result of the analysis is articulated into tourism governance index and management strategy based on Boston Consulting Group Matrix. This framework which later transformed into governance matrix can be used to set up governance index to help the government improve the governance performance. The android based app open access is also developed to bring policy making process closer to the community and global sphere.

Keywords: Sustainable Development Plus, Measuring Tourism Governance, Open Access Android Based App, Raja Ampat, Papua.
\end{abstract}

\footnotetext{
${ }^{1}$ Marlon Arthur Huwae is a Lecturer at University of Papua, West Papua, Indonesia. Email address: marlonarthurhuwae@gmail.com

${ }^{2}$ Fikri Muhamad Hanif and Klasina Rumbekwan are Staff at Departement of Tourism, Raja Ampat Regency Government, West Papua - Indonesia
} 


\section{Redefining Tourism Governance in Raja Ampat: Sustainable Development Plus, Governance Index and Android Based App Open Access}

Marlon Arthur Huwae, Fikri Muhamad Hanif and Klasina Rumbekwan

\section{Introduction}

\subsection{Background of problems}

As the globalisation, interconnectedness and interdependence between one state and other states are driven by strategic culture, the concept about measuring tourism governance should be built upon inclusive development. Similarly, the formula to quantify the tourism governance should consider the interest to be on better position of the community, the entrepreneur and other related stakeholders. The instrument elaborated in this paper is based on Fuentes (2013) in measuring tourism governance. It is developed further to classify the governance based on the performance on directive capacity and directive effectiveness. Based on that performance, the strategy to improve governance and to minimize corruption is provided. In addition, to enhance governance at national, regional and global level, a framework is provided. It is the long term goal of the author that the essence of the research can be articulated into android based apps to measure governance at national and regional level.

\subsection{The problems (research/paper questions)}

There are two research questions underlined; they are: 1) What is the current tourism governance index of Raja Ampat 2) How to better improve governance in Raja Ampat through open access app.

\section{II.. Concept to Measure Governance}

Shared ideology, mutual major interest to be on better position as well as vision are important to be integrated into inclusive yet sustainable development since it will give more positive impacts in the long run. In contrast focusing on dollar, environmental protection and current social condition without nurturing and taking mutual major interest and shared ideology will not keep the inclusive sustainable development in the long run.

Inclusive development consists of two important elements of the internal core and "layer" (external layer). The core part is divided into interest to be on better position", alliance (allied and gather support), engagement (involvement and participation rates), adoption (ability to adopt new ideas and to do so), and security (security of the physical, moral, spiritual peace to obtain social capital). The second element of the external layer is divided into social (empowerment socially), economy (empowerment economically), environment (use of natural resources in a sustainable manner), empowerment and governance and stewardship (governance governance and services that empower). The chart below presents the concept about inclusive development. 
Figure 1. Inclusive Development

\section{Core}

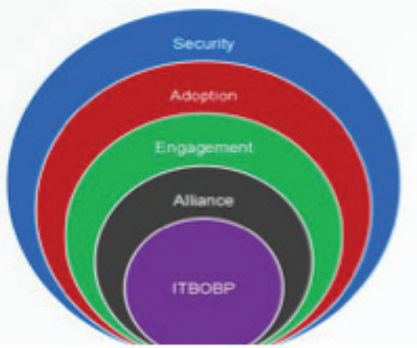

Layer

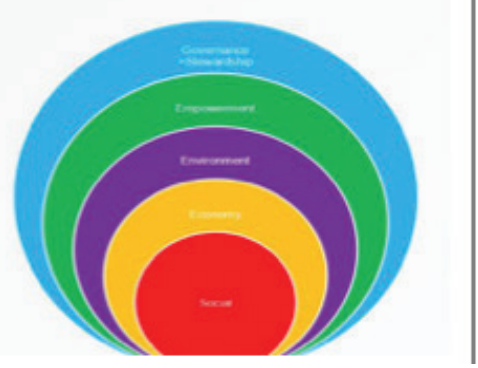

From the chart above, it is obvious that the core of inclusive development is interest to be in a better position (ITOBP). ITOBP is actually the agenda of all stakeholders including the community, the state and non state actors. ITOBP might be different from one stakeholder to other stakeholders so that it is important to find the common ground. As the common ground is identified, the stakeholders with same interest will form alliance. The Alliance is then reflected in the social interaction to make contact and interaction process (engagement) with new elements including good ideas and new programs initiated by the government or non-government parties. When performing those processes, the stakeholders collectively and individually perform the evaluation process to selectively adopt a new element and new strategyto pursue their interest. The adoption of new strategy is then expected to be carried out by the stakeholders to meet their needs for security in securing the interest to be on better position. The security in securing the interest to be on better position is the main capital to generate and to embrace development in social, economic and environmental sectors. The development can be initiated by state or non state actors. As the development is motorised and supported by the key stakeholders including the community, community and related stakeholders are empowered effectively. The sustainable empowerment needs good governance and stewardship. To be effective, governance and stewardship needs to be adaptive to deal with shock and change that might give negative impact on the empowerment of the community and the stakeholders.

\section{Method}

The formula to measure tourism governance is based on Fuentes (2013) in his book entitled "Governance for Tourism Sector and Its Measurement". According to Fuentes (2013), tourism ggovernance is "a practice of government that is measurable, that is aimed to effectively direct the tourism sectors at the different levels of government through forms of coordination, collaboration and/or cooperation that are efficient, transparent and subject to accountability, that help to achieve goals of collective interest shared by networks of actors involved in the sector, with the aim of developing solutions and opportunities through agreements based on the recognition of interdependencies and shared responsibilities".

There are two elements to measure tourism governance namely: directive capacity and directive effectiveness. Fuentes (2013) stated that basic approach to observation of the governance measurement in tourism sector relies on directive capacity and directive effectiveness; the directive capacity is related to government capacity and the directive effectiveness is related to government practice. Accordingly, the indicators used to measure 
directive capacity are 1)coordination, cooperation, and collaboration among Public Tourism Administration (PTAs) at different levels of government, 2) establishment of cooperative and collaborative public-private relation, 3) assurance of co-responsibility, transparency and accountability and the indicators used to measure directive effectiveness are 1)coordination, cooperation and collaboration among PTAs and other public sector actors and networks at different level of government and 2)cooperation and collaboration by public administrations with other non governmental actors and network of actors (Fuentes, 2013).

The formula of Fuentes (2013) about tourism governance measurement that is ideal but lacks of detail strategy is improved by the concept developed by Huwae and Scott (2017). The governance performance is assessed and analysed by considering the input from the government, business, experts and community. The result is converted into index which is based on governance matrix.that is classified into one star, two stars, three stars and four stars. By articulating the performance of directive capacity and directive effectiveness into governance matrix, the status of tourism governance can be effectively categorised into 4 section (classes). The chart below depicts governance matrix used to assess directive effectiveness and directive capacity.

Figure 2. Governance Matrix (Huwae and Scott, 2017)

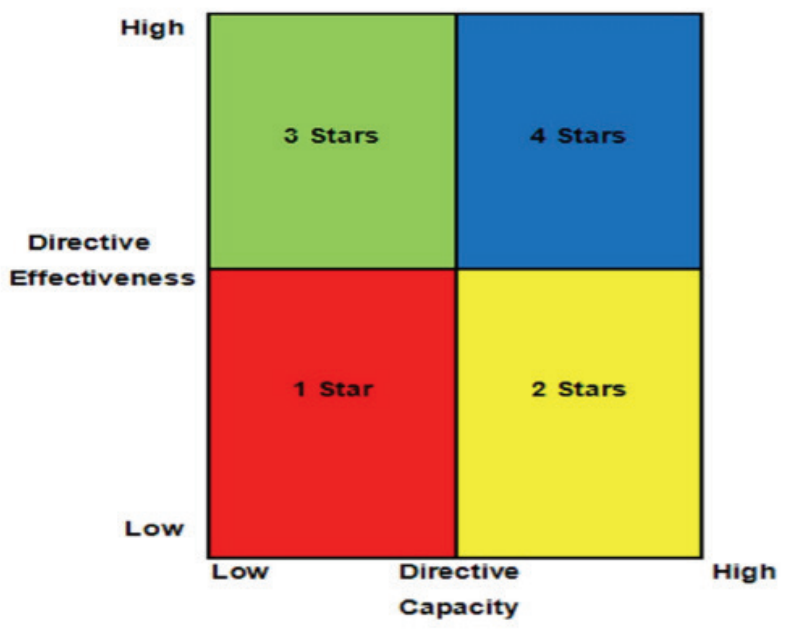

From the chart above, it is clear that each quadrant has different performance in directive capacity and directive effectiveness. Quadrant 1 (3 stars) means an institution or organisation has a high level of effectiveness directing but a low level of direct capacity. It means that the organisation needs to quickly prepare a strategy to build the capacity of directing including leadership, knowledge and technology transfer, training and professionalism improvement in minimum service standards.

Quadrant 2 (4 stars) means that an institution or organisation has a high level of directive effectiveness and a high level of directive capacity. This shows that the organisations need to prepare a strategy to retain existing performance by conducting monitoring and evaluation on a regular basis. However, it does not necessarily mean that the institution has already advance in all indicators, it is likely that even though the institution has 4 star level of governance, it still under performs in one or two indicators. Accordingly, the strategy to improve governance performance is still essential. 
Quadrant 3 (2 stars) means that the organisation or institution has a high directive capacity but experienced problems with the directive effectiveness. This shows that the organisations need to immediately prepare concrete steps to improve effectiveness in the conduct of collaboration, cooperation and coordination with other involved parties. Effectiveness in work requires improvement in terms of cooperation, collaboration and the values upheld in minimum service standards.

Quadrant 4 (1 star) means that the directive effectiveness and directive capacity are equally low. This means that organisations are characterised by the inability to implement the values of "good governance" and leadership is still not effectively done so professionalism is not maximised. The priority at this stage is to increase the organisational capacity through training, workshops and knowledge transfer that can be done in cooperation with other organisations that are more competent and able to implement practices and professionalism. Another thing that can be done is to provide training to appropriate staffs based on their expertise and duties. In addition, the data is collected through survey targeted the government and the community, bussiness at Sapokren, Raja Ampat.

\section{Result}

This section discusses the tourism governance index in Raja Ampat. Measurement of tourism governance in Raja Ampat is carried out by conducting internal assessment and external assessment. The internal assessment is carried out by active participation from all the government staff in the tourism department of Raja Ampat. Their input regarding the performance of tourism governance is analysed by evaluating the directive capacity and directive effectiveness of the tourism department of Raja Ampat. The external assessment, on the other hand, focus on the input from business, community, tourism operator, tourism activist, expert and Non Government Organisation regarding the governance performance including effort to minimize corruption done by the government. However, due to time and resource constraint, the external assessment is only conducted on Waisai including Sapokren. The index of tourism governance has two values based on the internal and external assessment. For internal assessment carried out by the government, the tourism department of Raja Ampat is classified as 4 star institution in terms of governance. The directive capacity is at 17.5 and the directive effectiveness is at 17.275 However, there is still room to improve governance especially about capacity to coordinate with non government agent. The assessment shows that the value for directive capacity in coordination with other non government agency as the lowest compared to other indicators. In addition, the directive effectiveness of the tourism department of Raja Ampat are less significant on:

- Effectiveness to work with non government agency

- Effectiveness to coordinate with non government agency

- Effectiveness to coordinate with other related government agency

- Transparency and accountability

- Effectiveness of the mechanism used to involve the business owner

- Effectiveness of the procedure in involving the non government agency

- Effectiveness in selecting partner and procurement

- Staff placement based on skill and capacity

- Effectiveness of monitoring and minimum service standard to support trans- parency, 
accountability and eradicate rent seeking and corruption.

The matrix below depicts the position of tourism department of Raja Ampat.

Figure 3. Internal Assessment and Tourism Governance Index of Department of Tourism, Raja Ampat

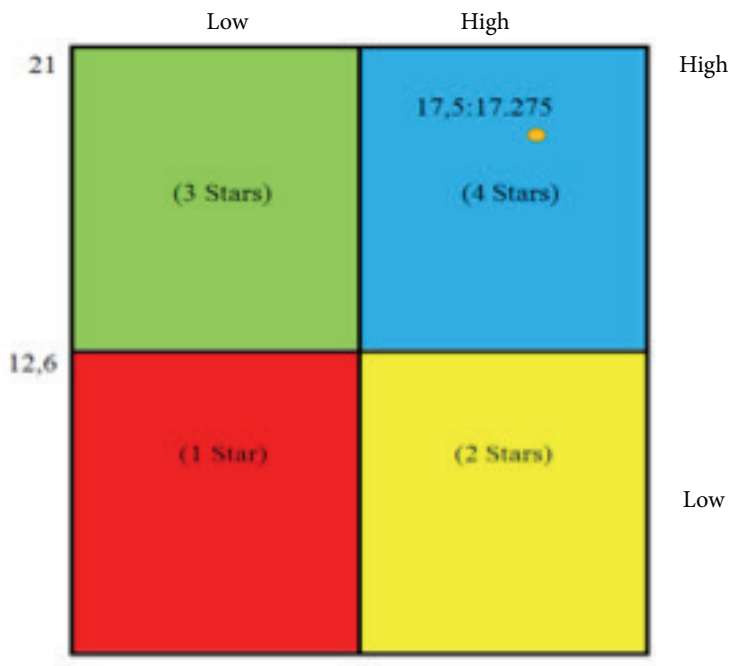

The external assessment is carried out to have better data triangulation and better holistic assessment. The external assessment is conducted in Waisai including Sapokren Raja Ampat. Similar to the tourism governance index in internal assessment, the external assessment show that the tourism governance in Raja Ampat is at 4 stars classification. The directive capacity is at 11.12 and the directive effectiveness is at 11.36. Even though, Raja Ampat has 4 stars classification of tourism governance, there are still rooms to improve. In terms of directive capacity, the government of Raja Ampat is still less strong at:

- Capacity of government in collaborating with community and tourism activist regarding tourism program

- Capacity of government in involving the community to participate in tourism program

- Capacity of government in providing access to information about tourism program

- Capacity of government in empowering community and tourism operator through tourism program

- Capacity of government related to transparency and accountability of tourism program

- Capacity of government in communicating and coordinating with community and tourism operator

- Capacity of government in involving the community and tourism operator in decision making and policy making process

- Capacity of government in improving the skill and capability of community and tourism operator in tourism sector

In addition, the commuity are still weak on the capacity of community and tourism operator to carry our tourism program, capacity of community and tourism operator in managing tourism object, culture of cooperation in community, openness to 
foreigners, and capacity of community in supporting "Sapta Pesona".

In terms of directive effectiveness, the government is still less strong in:

- Effectiveness of cooperation procedure between government and community

- Effectiveness of the media used by the government to communicate with the community and tourism operator

- Effectiveness of procedure used by government in involving the community in tourism program

- Effectiveness of the mechanism used by the government to develop tourism object

- Effectiveness of the government in transparency and accountability of tourism program which is done in collaboration with the community

- Effectiveness of the approach used by the government to empower the community

- Effectiveness of the approach used by the government to involve the community in decision making and policy making.

- Effectiveness of the approach used by the government in improving the skill of community and tourism operator that are related to tourism

- Effectiveness of the government procedure in involving the community to run tourism program

- The community, on the other hands, is less strong in:

- Effectiveness of the community strategy in managing the tourism object

- Effectiveness of the community and tourism operator in dealing with the social impact of tourism development

- Effectiveness of the community and tourism operator in supporting Sapta Pesona

- Effectiveness of the community and tourism operator to nurture positive culture including collaboration and cooperation

- Effectiveness of the strategy used by the community and tourism operator to convey input and complaint to the government in order to develop tourism sector

The matrix below shows the tourism governance based on external assessment.

Figure 4. Tourism Governance of Raja Ampat Based on

External Assessment.

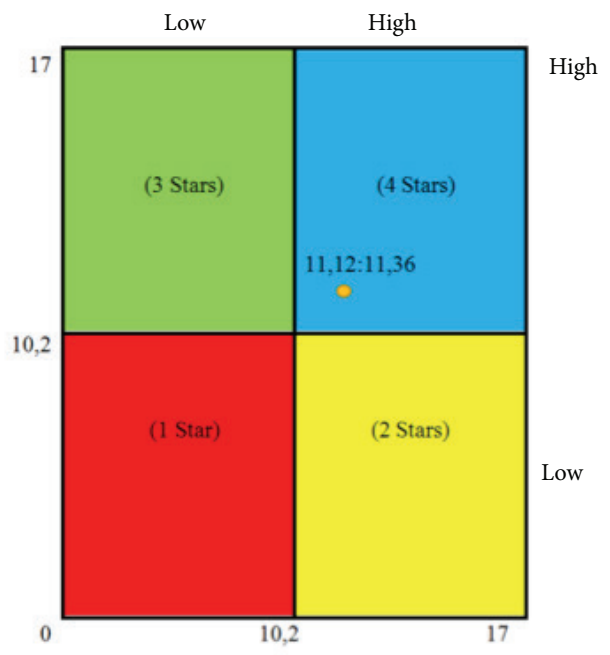




\section{Discussion}

It is important to explain the implication of the result. The result shows that there is different view regarding the governance carried out by Dinas Pariwisata Raja Ampat. The internal assement is different from external assessment. In the light of minimizing corruption, the result of internal assessment shows that the wekaness of Dinas Pariwisata Raja Ampat in minimizing corruption relies on the effectiveness of government in strenghtening accountability and transparency related to tourism program. However, the result of external assessment with respondents from community and bussiness indicates that the weaknes of Dinas Pariwisata Raja Ampat in minimizitng corruptino is not only related to the the effectiveness of government in strenghtening accountability and transparency related to tourism program but also related to the capacity of the government related to transparency and accountability of tourism program.

Accordingly, it is important to have open access app and website that enable the local government, and community, bussines and tourist to better measure governance and to better minimize corruption. The app is in fact has been built and it is called Serve IndoKonor. The main feature of the app is that it embraces bottom up approach and it can promote regional and global tourism governance.

\subsection{Website and Open Access Apps to Measure Tourism Governance in Raja Ampat and To Promote Global Tourism Governance}

Website and open access apps to measure tourism governance can be done in top down and bottom up approach. This apps should take into account the forces of strategic culture namely leadership and resource allocation associated with it as well as the ideology of state in engaging with interdependence and interconnectedness. There are four main key players in the development and fruitful use of the apps. They are the international body, the user, the crowd-sources and the innovator functioning as the app developer.The international body plays a key role in the establishment of the apps and indicators of tourism governance measurement. It also plays major role in identifying leader at sub-global level and manage the crowd-source.

The top down approach is applied in the establishment of one set of apps with standardised indicators in measuring the tourism governance. The bottom up approach is reflected on the acceptance of feedback and initiative from the members regarding the measurement and initiative to establish a hub of sub regional tourism governance measurement and its governing body. Accordingly, resource allocation, leadership and capability to support knowledge and technology transfer are essential.

As this apps is also aimed at bringing the governance closer to the community and key stakeholders in tourism, the users play major role in utilising the apps properly and in encouraging all related stakeholders to use the apps. For this reason, the state institution for tourism development as well as non state actors are likely to be the leading actors. To support them, the international governing body might enhance knowledge and technology transfer especially in establishing apps for national and regional level.

In addition, the crowd-sources play major role in providing constructive inputs regarding the measurement, and the establishment of a hub of sub regional tourism governance measurement and its governing body. It is expected that the crowd-sources are 
able to identify the common ground that might strengthen cohesiveness between countries in one region. The following chart depicts the hierarchy of the actors in promoting global tourism governance through open access apps based on Huwae and Scott (2017).

Figure 5. Hierarchy and Function of Stakeholders in promoting Global Tourism governance via open access apps.

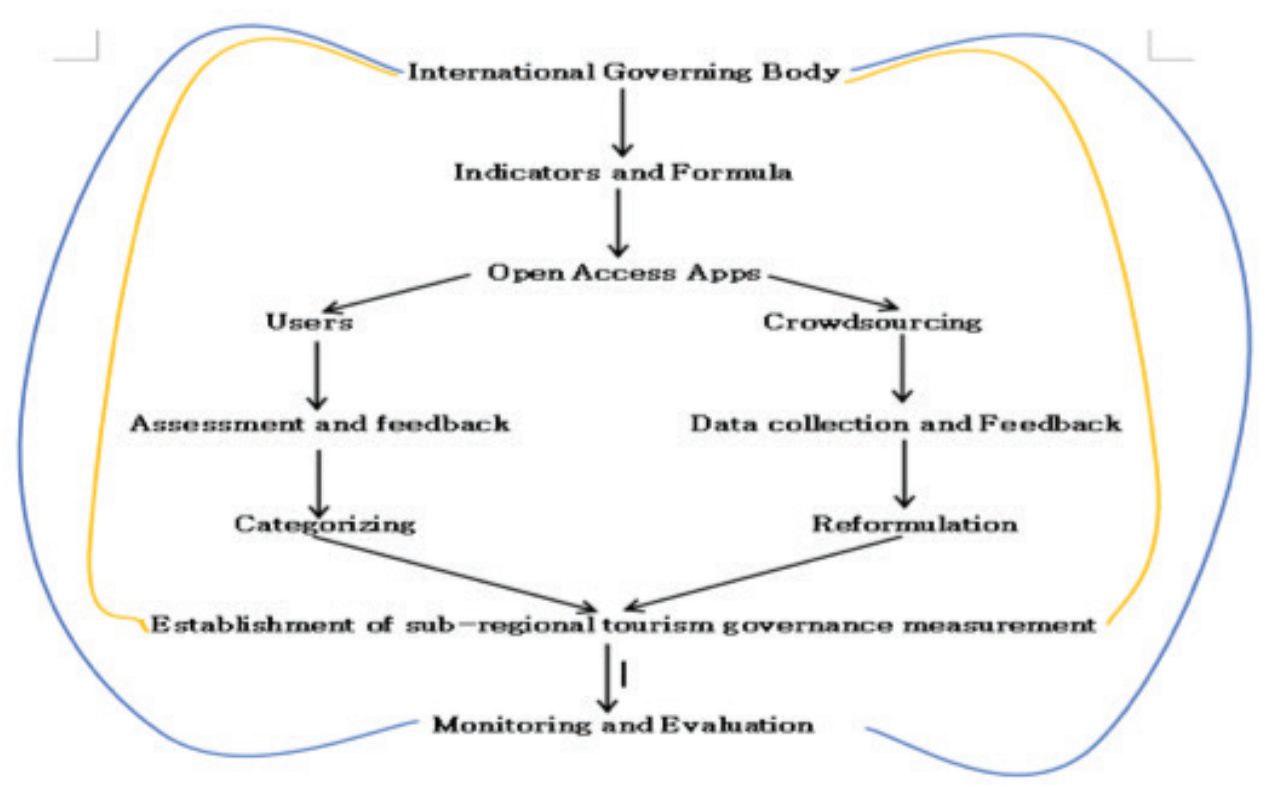

The previous chart shows 8 significant activities that promote global tourism governance by the combination of top down and bottom up approach. The top down approach is reflected on the activities related to the establishment of the indicators and the apps. It is clear that this activities are managed by international governing body. A mix of top down and bottom up approach is articulated on the activities related to assessment and feedback as well as data collection and feedback. The assessment and feedback are conducted by the user of apps which might be dominated by state tourism institution and non state actors. Feedback is then given to the international governing body regarding the flexibility of the apps in dealing with different characteristic of state and tourism development. At this stage, states can be categorised based on the commitment, the performance of tourism governance and barrier in tourism governance. It is also expected that technology and knowledge transfer are given to the state that has commitment to build similar apps for sub national scope or regional scope.

In addition, the activities related to data collection and feedback deal with professionals employed by state, non government organisation and university. They are expected to give review regarding the apps as well as strategy to enhance global governance. Their review will improve the quality of the apps and provide insight about the common ground of the states in particular region. This is done by the reformulation of the tourism governance that fits to the need of regional level.

The bottom up approach is reflected on the activities related to the establishment of sub global tourism governance body, monitoring and evaluation. The establishment of sub-global tourism governance measurement and its governing body is based on the 
feedback, needs, aspiration and commitment of group of states. This might be supported by international governing body by taking into consideration the geographical location, economic development, and tourism governance performance. It is important to identify leader on sub-regional tourism governance. In addition, the monitoring and evaluation are conducted by international governing body to obtain feedback about the outcome of the apps, and constructive input to improve the apps and the leadership capacity of the international governing body.

\subsection{Serve IndoKonor as the Bottom Up Android Based App and Website to Measure Tourism Governance in Raja Ampat.}

Serve IndoKonor is built and developed by a team led by academe from University of Papua to bring the policy making process closer to the community. This app is available on play store. One main feature of this app is that the governance performance is not only generated from the government perspective but also from other key stakeholders such as community, expert and business. Accordingly, the result is more on the bottom up approach compared to top down approach. By the support from the government of Australia through the Alumni Grants Scheme, the innovators and policy strategist which are the alumni of Australia Awards Indonesia are able to develop app to measure tourism governance in Raja Ampat.

Serve IndoKonor is an app and website developed to bring the policy making process closer to the community, the business and the expert. The app is able to provide strategy based on the tourism governance index generated from the governance matrix (Huwae and Scott, 2017). Serve IndoKonor is also equipped with feature "Lapor" that is able to give access for the community, business, tourism expert and Non Government Organisations to give feedback regarding the environmental issue in Raja Ampat. The app provides media for the users to upload the picture regarding tourism activity that gives harmful impact for the environment as well as other activities that gives negatives impact on environmental sustainability.

Moreover, it is important to have scheme in measuring the tourism governance through open access app. The scheme should enhance two way interactions between the governing body and the users and it should be able to do data triangulation as well as accommodate data verification. The apps should be able to measure the data from the informant and it should be able to accommodate data inventory as means of verification. As illustration, the data obtained from the informant regarding effectiveness of government in cooperation with third party can be verified with the agreement and memorandum of understanding signed by both the government and the third party. The apps should also quantify the data from the field especially for the area where internet connection is not available. It is very important to have better picture and analysis regarding the performance of the government from the field perspective. From the robust assessment, the apps should give appropriate strategy based on the governance matrix

The following chart explains the scheme in measuring tourism governance through open access apps. 
Figure 6. The Scheme in Measuring Governance Through Open Access Apps.

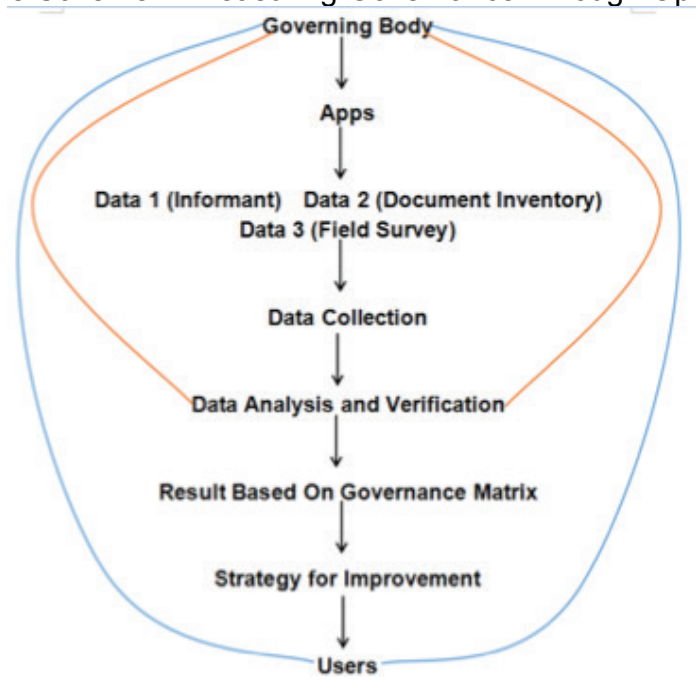

\section{Conclussion and Recommendation}

\subsection{Conclussion}

International governing body, local and national government play key role in nurturing global tourism governance. In this case, leadership capacity and resource are essential to do bottom up and top down approach. The combination of bottom up and top down approach is essential to support sub global tourism governance. This can be done by considering forces that affect strategic culture and open access apps that concerns with strategic culture. It is also important to take into consideration the inclusive development concept in managing the tourism. The development of Serve IndoKonor android based app is likely to give positive change tourism development in Raja Ampat as well as in the effort to minimize corruption.

\subsection{Recommendation}

1. It is strongly recommended that the government of Indonesia can replicate governance matrix, governance measurement and open access app to better improve service delivery, to better synchronize the government vission and community needs and to better improve governance as well as to bring the policy making process closer to the community.

2. To improve ServeIdoKonor, it is recommended (i) to add geographic position system on the app so that when the user reports any activity related to environmental issue, the app also captures the exact location of the site where the accident takes place, (ii) to upgrade the load system of the app because at the moment the app can accommodate maximally 5,000 user at one time, (iii) to have language feature in the app, so that the user can set the language to several options including Indonesia, Malay Papua, English, and China.

\section{Refferences}

Fuentes, CD.2013, Governance For Tourism Sector and Its Measurement, Statistic And TSA Issue Paper Series, UNWTO.

Huwae,M \& Scott, N, 2017, Measuring Institutional Effectiveness and Governance, UNW-

TO. 